\title{
Design of novel high strength bainitic steels: Part 1
}

\author{
F. G. Caballero, H. K. D. H. Bhadeshia, and K. J. A. Mawella, D. G. Jones, \\ and P. Brown
}

Mixed microstructures consisting of fine plates of upper bainitic ferrite separated by thin films of stable retained austenite have seen many applications in recent years. There may also be some martensite present, although carbides are avoided by the judicious use of silicon as an alloying element. The essential principles governing the optimisation of such microstructures are well established, particularly that large regions of unstable high carbon retained austenite must be avoided. With careful design, impressive combinations of strength and toughness have been reported for high silicon bainitic steels. The aim of the present work was to ascertain how far these concepts could be extended to achieve unprecedented combinations of strength and toughness in bulk samples subjected to continuous cooling transformation, consistent with certain hardenability and processing requirements. Thus, this paper (part 1 of a two part study) deals with the design, using phase transformation theory, of a series of bainitic alloys, given a set of industrial constraints. Part 2 of the study concerns the experimental verification of the design process.

At the time the work was carried out Dr Caballero and Professor Bhadeshia were in the Department of Materials Science and Metallurgy, University of Cambridge, Pembroke Street, Cambridge CB2 3QZ, UK (hkdb@cus.cam.ac.uk). Dr Caballero is now at CSIC, CNIM, Avda Gregorio del Amo, 8-28040 Madrid, Spain (fgc@cenim.sic.es). Dr Mawella, Mr Jones, and Dr Brown are in the Structural Materials Centre, Defence Evaluation Research Agency, R1079, Building A7, Farnborough, Hants GU14 OLX, UK. Manuscript received 13 March 2000; accepted 7 August 2000.

(C) 2001 IoM Communications Ltd.

\section{Introduction}

High strength bainitic steels have not been as successful in practice as quenched and tempered martensitic steels, because the coarse cementite particles in bainite are detrimental to toughness. However, the precipitation of cementite during bainitic transformation can be suppressed by alloying the steel with about $1.5 \% \mathrm{Si}^{*}$, which has very low solubility in cementite and greatly retards its growth from austenite. ${ }^{1-12}$ The carbon that is rejected from the bainitic ferrite enriches the residual austenite, thereby stabilising it down to ambient temperature. The resulting microstructure consists of fine plates of bainitic ferrite separated by carbon enriched regions of austenite.

This mixed microstructure is, in principle, an ideal combination from many points of view. In particular, the steel has a high resistance to cleavage fracture and void formation due to the absence of fine carbides. There is then the possibility of improving simultaneously the strength and toughness because of the ultrafine grain size of the bainitic ferrite plates, and of further enhancing the toughness by a transformation induced plasticity effect.

In spite of these promising advantages, the bainitic ferrite-austenite microstructure has on many occasions failed to live up to its full potential, primarily because of the instability of relatively large or blocky regions of austenite, which become trapped between sheaves of bainite. ${ }^{8,13}$ The blocks of austenite tend to transform to high carbon, untempered martensite under the influence of small stresses and consequently have an embrittling effect. By contrast, the films of austenite that are trapped between the platelets of ferrite in a sheaf are much more stable, partly because of their higher carbon concentration, but also because of the constraint to transformation exerted by the surrounding plates of ferrite.

Therefore, every effort has to be made to reduce the fraction of blocky austenite present in the microstructure

*Compositions are given in wt- $\%$ throughout. and increase its stability with respect to martensitic transformation. The aim of alloy design should then be to increase the maximum permitted degree of transformation to bainitic ferrite. There may be other constraints, for example, the need to ensure that the hardenability of the steel is sufficient for industrial production.

There are applications in the defence industries where secondary hardened martensitic steels are used in the manufacture of large components shaped by forging. The minimum strength and toughness required are $1100 \mathrm{MPa}$ and $125 \mathrm{MPa} \mathrm{m}^{1 / 2}$, which have never been achieved with mixed microstructures of bainite and austenite. The aim of the present work was to ascertain to what extent the concepts of bainite transformation theory could be exploited to achieve unprecedented combinations of strength and toughness in bulk samples subjected to continuous cooling transformation, consistent with certain hardenability and processing requirements. Part 1 of the study deals with the design, using phase transformation theory, of a series of bainitic alloys, given a set of industrial constraints. Part $2^{14}$ is concerned with the experimental verification of the design process.

\section{Modelling of microstructure and properties}

IMPROVEMENT OF TOUGHNESS: $T_{0}^{\prime}$ CURVE

The bainite transformation progresses by the diffusionless growth of tiny platelets known as 'subunits'. The excess carbon in these platelets partitions into the residual austenite soon after the growth event. Diffusionless growth of this kind can only occur if the carbon concentration of the residual austenite is below that given by the $T_{0}^{\prime}$ curve. The $T_{0}$ curve is the locus of all points, on a temperature versus carbon concentration plot, where austenite and ferrite of the same chemical composition have the same free energy. The $T_{0}^{\prime}$ curve is defined similarly, but taking into account the stored energy of the ferrite due 
to the displacive mechanism of transformation. It follows that the maximum amount of bainite that can be obtained at any temperature is limited by the fact that the carbon content of the residual austenite must not exceed the $T_{0}^{\prime}$ curve on the phase diagram. ${ }^{15-18}$

The $T_{0}^{\prime}$ concept can be used to optimise the mechanical properties by minimising blocky, unstable austenite. ${ }^{8,9} \mathrm{An}$ increase in the amount of bainitic ferrite in the microstructure is required in order to consume the blocks of austenite.

The variation of the carbon content of austenite $x_{\gamma}$ as a function of the average carbon content of the alloy $\bar{x}$ and the volume fraction of bainitic ferrite $V_{\mathrm{B}}$ is given by

$$
x_{\gamma}=\bar{x}+V_{\mathrm{B}} \frac{(\bar{x}-s)}{\left(1-V_{\mathrm{B}}\right)}
$$

where $s$ is the amount of carbon trapped in the bainitic ferrite, either in solid solution $(s=0.03 \%)$, or in the form of carbides $(s=0 \cdot 27 \%)$.

Previous work ${ }^{7,15}$ suggested two main methods of increasing the maximum permitted degree of transformation to bainitic ferrite:

(i) by reducing the overall carbon content $\bar{x}$ of the alloy concerned, so that the critical concentration in the austenite at which displacive transformation becomes impossible is reached at a later stage (and hence a higher $V_{\mathrm{B}}$ ) in the transformation (equation (1)) - of course, this is only useful if the reduction of the overall carbon content of the alloy does not at the same time lead to a decrease in the strength of the microstructure

(ii) by modifying the substitutional alloying elements such that the $T_{0}^{\prime}$ curve is shifted to higher austenite carbon concentrations. ${ }^{7,8,15}$

\section{TIME - TEMPERATURE - TRANSFORMATION (TTT) DIAGRAMS}

Apart from controlling the $T_{0}^{\prime}$ curve, substitutional solutes also affect hardenability which is an important design parameter since industrial manufacturing generally involves continuous cooling transformation. For this purpose, a thermodynamic method ${ }^{19}$ is used which was developed to allow the estimation of isothermal transformation diagrams from a knowledge of the chemical composition of the steel concerned.

The TTT diagram is treated as being composed of two overlapping $\mathrm{C}$ curves, one representing the diffusional ferrite and pearlite transformations, and the other representing the displacive Widmanstätten ferrite and bainite reactions. It is possible to predict relative shifts in these component curves, as a function of alloying element content, thus making the technique potentially useful in the theoretical steel design.

\section{DEFORMATION MODEL FOR THREE PHASE \\ ALLOYS}

As a further step, a model for calculating the strength of the mixed microstructure has been developed as an aid in the design process.

In a multiphase alloy, each phase contributes to the overall properties of the aggregate. If the contributions from each phase are independent, then the properties of the multiphase alloy will be a weighted average of the properties of the individual phases. However, the properties of the aggregate may be influenced by interactions among the phases. Two simple models, equal strain and equal stress, have often been employed to estimate the flow curve of a two phase alloy from those of the constituent phases. ${ }^{20}$ Sometimes, composites of the above two models have also been considered. ${ }^{21,22}$ However, these models are not based on a detailed consideration of solid mechanics.
In this work, an attempt has been made to calculate the stress-strain curve of a microstructure consisting of bainitic ferrite separated by carbon enriched regions of austenite and some martensite. This three phase microstructure has, for the purposes of calculations, been treated as a mixture of two phases, a hard phase consisting of bainite and martensite, and a soft phase, which is austenite.

One model successfully used to obtain the deformation parameters of two phase alloys is that of Tomota et al. ${ }^{23}$ where the internal stresses produced by the inhomogeneous distribution of plastic strain are taken into account. Furthermore, the stress and strain distributions in the component phases can be followed at every stage of the deformation process. It is assumed that the true stress $\sigma-$ true strain $\varepsilon$ behaviour of the mixed microstructure and of the component phases can be represented by a power law of the form

$$
\sigma=K \varepsilon^{\mathrm{n}}
$$

where $K$ is the strength coefficient and $n$ is the strain hardening coefficient.

The applied stress before the onset of plastic deformation in the hard phase is given by

$$
\sigma_{\mathrm{m}}=\sigma_{\mathrm{s}}\left(\frac{\varepsilon_{\mathrm{m}}}{1-f}\right)+\frac{f}{1-f} A \varepsilon_{\mathrm{m}}
$$

with

$$
\varepsilon_{\mathrm{m}}=(1-f) \varepsilon_{\mathrm{s}} \text { and } A=\frac{E(7-5 v)}{10\left(1-v^{2}\right)}
$$

where $\sigma_{\mathrm{m}}$ and $\varepsilon_{\mathrm{m}}$ are respectively the true stress and true plastic strain in the material as a whole, $f$ is the volume fraction of the harder phase (bainite + martensite), $\sigma_{\mathrm{s}}$ and $\varepsilon_{\mathrm{s}}$ are respectively the true flow stress and true plastic strain of the soft phase, $E$ is Young's modulus (taken to be $210 \mathrm{GPa}$ ), and $v$ is Poisson's ratio (taken to be 0.33 ).

The onset of plastic flow in the harder phase is represented by the following set of simultaneous equations

$$
\begin{aligned}
\sigma_{\mathrm{m}}^{\mathrm{c}} & =\sigma_{\mathrm{s}}\left(\frac{\varepsilon_{\mathrm{m}}^{\mathrm{c}}}{1-f}\right)+\frac{f}{1-f} A \varepsilon_{\mathrm{m}}^{\mathrm{c}} \\
\sigma_{\mathrm{m}}^{\mathrm{c}} & =\sigma_{\mathrm{ho}}-A \varepsilon_{\mathrm{m}}^{\mathrm{c}} \quad . . .
\end{aligned}
$$

where $\sigma_{\mathrm{m}}^{\mathrm{c}}$ and $\varepsilon_{\mathrm{m}}^{\mathrm{c}}$ are respectively the critical true stress and plastic strain to start yielding in the harder phase, and $\sigma_{\mathrm{ho}}$ is the true yield stress for the harder phase.

Further deformation is calculated for small strain increments from the following simultaneous equations

$$
\begin{aligned}
& \sigma_{\mathrm{s}}\left(\frac{\varepsilon_{\mathrm{m}}^{\mathrm{c}}}{1-f}+\delta \varepsilon_{\mathrm{s}}\right)=\sigma_{\mathrm{m}}-f A\left[\frac{\varepsilon_{\mathrm{m}}^{\mathrm{c}}}{1-f}+\delta \varepsilon_{\mathrm{s}}-\delta \varepsilon_{\mathrm{h}}\right] \\
& \sigma_{\mathrm{h}}\left(\delta \varepsilon_{\mathrm{h}}\right)=\sigma_{\mathrm{m}}+(1-f) A\left[\frac{\varepsilon_{\mathrm{m}}^{\mathrm{c}}}{1-f}+\delta \varepsilon_{\mathrm{s}}-\delta \varepsilon_{\mathrm{h}}\right]
\end{aligned}
$$

where $\sigma_{\mathrm{h}}$ is the true flow stress of hard phase, and $\delta \varepsilon_{\mathrm{s}}$ and $\delta \varepsilon_{\mathrm{h}}$ are strain increments in the soft and hard phases, respectively.

Thus, the complete stress-strain curve for the mixed microstructure can be computed. However, this mathematical procedure can only be applied if the true stress - true strain relationships (equation (2)) of the component phases are known.

Young and Bhadeshia ${ }^{24}$ calculated the strength of a mixed microstructure of bainite and martensite, including constraint effects and changes in martensite composition (and hence strength) as bainite forms. According to them, the strength of martensite and bainite as individual phases can be factorised into a number of intrinsic components

$$
\sigma=\sigma_{\mathrm{Fe}}+\sum \sigma_{\mathrm{ss}, \mathrm{i}}+\sigma_{\mathrm{C}}+K_{\mathrm{L}}\left(\bar{L}_{3}\right)^{-1}+K_{\mathrm{D}} \rho_{\mathrm{D}}^{1 / 2}
$$

where $K_{\mathrm{L}}$ and $K_{\mathrm{D}}$ are constants, $\sigma_{\mathrm{Fe}}$ is the strength of pure annealed iron, $\sigma_{\mathrm{ss}, \mathrm{i}}$ is the solid solution strengthening due to 
substitutional solute $i, \sigma_{\mathrm{C}}$ is the solid solution strengthening due to carbon, $\bar{L}_{3}$ is a measure of the ferrite plate size, and $\rho_{\mathrm{D}}$ is the dislocation density.

In addition, the strength of constrained bainite may be represented by the equation

$$
\sigma_{\mathrm{B}} \approx \sigma_{\mathrm{B}}^{\prime}\left[0.65 \exp \left(-3 \cdot 3 V_{\mathrm{B}}\right)+0 \cdot 988\right] \leqslant \sigma_{\mathrm{M}}
$$

where $\sigma_{\mathrm{B}}$ and $\sigma_{\mathrm{B}}^{\prime}$ represent the strength of constrained and unconstrained bainite respectively, $\sigma_{\mathrm{M}}$ is the strength of martensite, and $V_{\mathrm{B}}$ is the volume fraction of bainitic ferrite. The model used by Young and Bhadeshia and experimental data from Coldren et $a l^{25}$ have been applied to estimate the empirical constants in equation (2) for the harder phase (bainite + martensite).

On the other hand, the method used to estimate the strength of austenite assumes that the strength in the softer phase is the result of three strengthening contributions: the strength of pure austenite iron in a fully annealed condition, solid solution strengthening due to carbon, and solid solution strengthening due to substitutional solutes. Thus, the true stress - true strain relationship of the soft phase or austenite has been calculated using the estimated value of the strength, and experimental hardness results reported by Bhadeshia and Edmonds. ${ }^{8}$ The derived values of $K$ and $n$ for the soft and harder phases are given in Table 1.

The results of the inhomogeneous deformation analysis using the Tomota et al. method, together with experimental tensile results, are shown in Fig. 1 for $\mathrm{Fe}-0 \cdot 2 \mathrm{C}-2 \mathrm{Si}-3 \mathrm{Mn}$ and $\mathrm{Fe}-0 \cdot 4 \mathrm{C}-2 \mathrm{Si}-4 \mathrm{Ni}$ alloys studied in previous investigations. ${ }^{8,9}$ Good agreement between experimental and calculated values of the maximum load has been found in the alloys studied. However, this model does not reproduce the low yield strength in the early stages of deformation caused by the presence of austenite in the microstructure. ${ }^{26}$ This model could therefore be used to evaluate only the maximum load of any proposed alloy.

\section{Design of new alloys}

The aim of this work was to design bainitic alloys for defence applications. The engineering requirements are for a Charpy $\mathrm{V}$ notch impact energy of $40 \mathrm{~J}$ at $-40^{\circ} \mathrm{C}$, fracture toughness $K_{\mathrm{IC}} 125 \mathrm{MPa} \mathrm{m}^{1 / 2}$, proof strength (YS) $1000 \mathrm{MPa}$, and tensile strength (UTS) $1100 \mathrm{MPa}$. A minimum ductility of $12 \%$ elongation and $50 \%$ reduction of area are also required.

Previous research, carried out by Bhadeshia and Edmonds $^{8,9}$ and Miihkinen and Edmonds ${ }^{10-12}$, on two silicon containing steels, nominally, $\mathrm{Fe}-0 \cdot 2 \mathrm{C}-2 \mathrm{Si}-3 \mathrm{Mn}$ and $\mathrm{Fe}-0.4 \mathrm{C}-2 \mathrm{Si}-4 \mathrm{Ni}$, showed that these alloys hold promise. The $\mathrm{Fe}-0 \cdot 2 \mathrm{C}-2 \mathrm{Si}-3 \mathrm{Mn}$ alloy exhibited excellent fracture toughness $\left(K_{\mathrm{IC}}=160 \mathrm{MPa} \mathrm{m}{ }^{1 / 2}\right)$ in the strength range $1375-1440 \mathrm{MPa}$ as isothermally heat treated at $250^{\circ} \mathrm{C}$. This fracture toughness is better than or equal to that of quenched and tempered AISI 300M and AISI 4340 steels at equivalent strength levels and approaches that of $18 \% \mathrm{Ni}$ maraging steel. ${ }^{12}$ Because of the increased carbon

Table 1 Values of strength coefficients $K$ and strain hardening coefficients $n$ considered in deformation model (subscripts $s$ and $h$ denote soft and hard phase respectively)

\begin{tabular}{lllll}
\hline Alloy composition*, wt-\% & $\kappa_{\mathrm{s}}, \mathrm{MPa}$ & $\kappa_{\mathrm{h}}, \mathrm{MPa}$ & $n_{\mathrm{s}}$ & $n_{\mathrm{h}}$ \\
\hline $\mathrm{Fe}-0 \cdot 2 \mathrm{C}-2 \mathrm{Si}-3 \mathrm{Mn}$ & 1254 & 2332 & 0.2 & 0.04 \\
$\mathrm{Fe}-0 \cdot 4 \mathrm{C}-2 \mathrm{Si}-4 \mathrm{Ni}$ & 1558 & 2786 & 0.2 & 0.04 \\
\hline
\end{tabular}

*These two silicon containing alloys were studied in previous investigations $\mathrm{s}^{8,9}$ and from that work were thought to be potentially investigations
useful for the present design process.
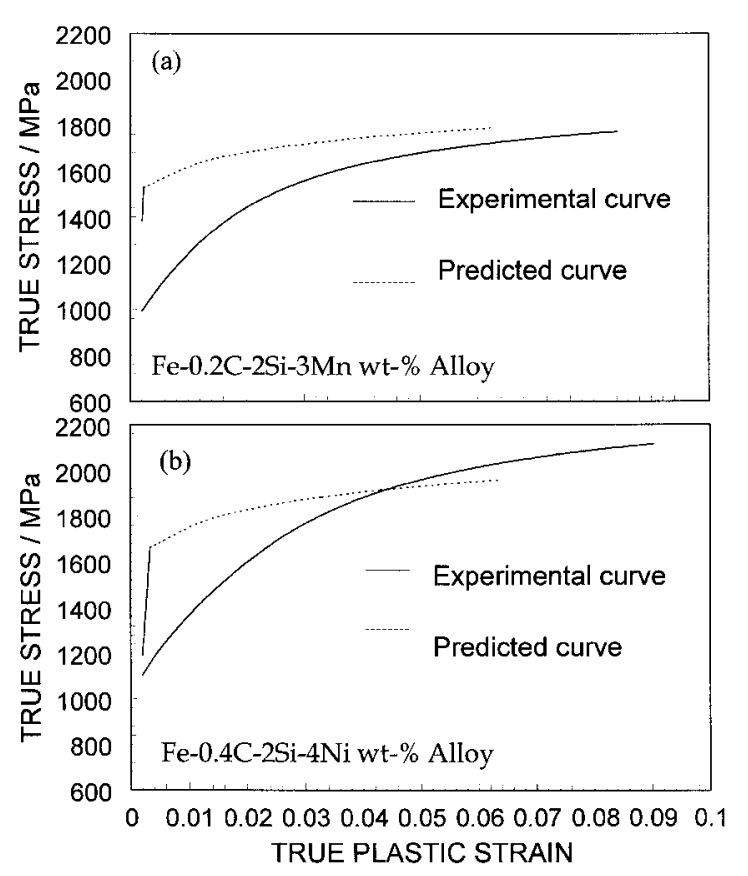

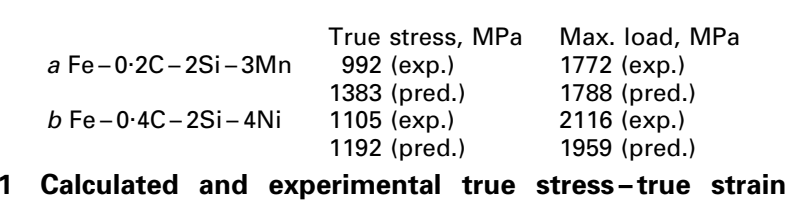
curves

content, higher strength levels $1500-1840 \mathrm{MPa}$ were obtained in the $\mathrm{Fe}-0.4 \mathrm{C}-2 \mathrm{Si}-4 \mathrm{Ni}$ alloy, with lower fracture toughness values, but this still exceeded those of commercial high strength martensitic steels. The original experiments $^{8,9}$ were carried out in order to demonstrate the role of the $T_{0}^{\prime}$ curve in greatly influencing the mechanical properties of carbide free bainitic steels. The experimental alloys developed for this purpose are not necessarily the optimum alloys from the point of view of mechanical properties. The present aim was to use a combination of the models described above to produce the best possible alloys, with microstructures produced by continuous cooling transformation, building on the previous work. ${ }^{8,9}$

Using the models, together with some background knowledge, the following modifications were proposed to increase the maximum volume fraction of bainite in the final microstructure and to improve the hardenability of the steels.

1. The silicon content was reduced to a level believed to be the minimum required to suppress carbide precipitation, i.e. $1 \cdot 5 \% \mathrm{Si}$. This should lead to an improvement in the impact toughness, without deterioration in the $T_{0}^{\prime}$ criterion or the hardenability.

2. With the aim of increasing the strength of the $\mathrm{Fe}-$ $0 \cdot 2 \mathrm{C}-2 \mathrm{Si}-3 \mathrm{Mn}$ alloy, the carbon content was increased to $0.3 \%$ with a reduction in the manganese content to $2 \%$ to retain toughness. It was found that the $T_{0}^{\prime}$ curve shifts to higher carbon when the manganese content is reduced. However, a reduction in manganese naturally reduces hardenability.

3. To increase the toughness of the $\mathrm{Fe}-0 \cdot 4 \mathrm{C}-2 \mathrm{Si}-4 \mathrm{Ni}$ alloy, the amount of carbon was reduced to $0.3 \%$. Calculations show that the hardenability did not seem to change appreciably.

4. Substantial improvements in both strength and hardenability were obtained by adding $1.44 \% \mathrm{Cr}$ to the nickel alloy. However, the $T_{0}^{\prime}$ curve was found to shift to much lower carbon concentrations. Finally, the nickel content 
Caballero et al. Design of novel high strength bainitic steels: Part 1515
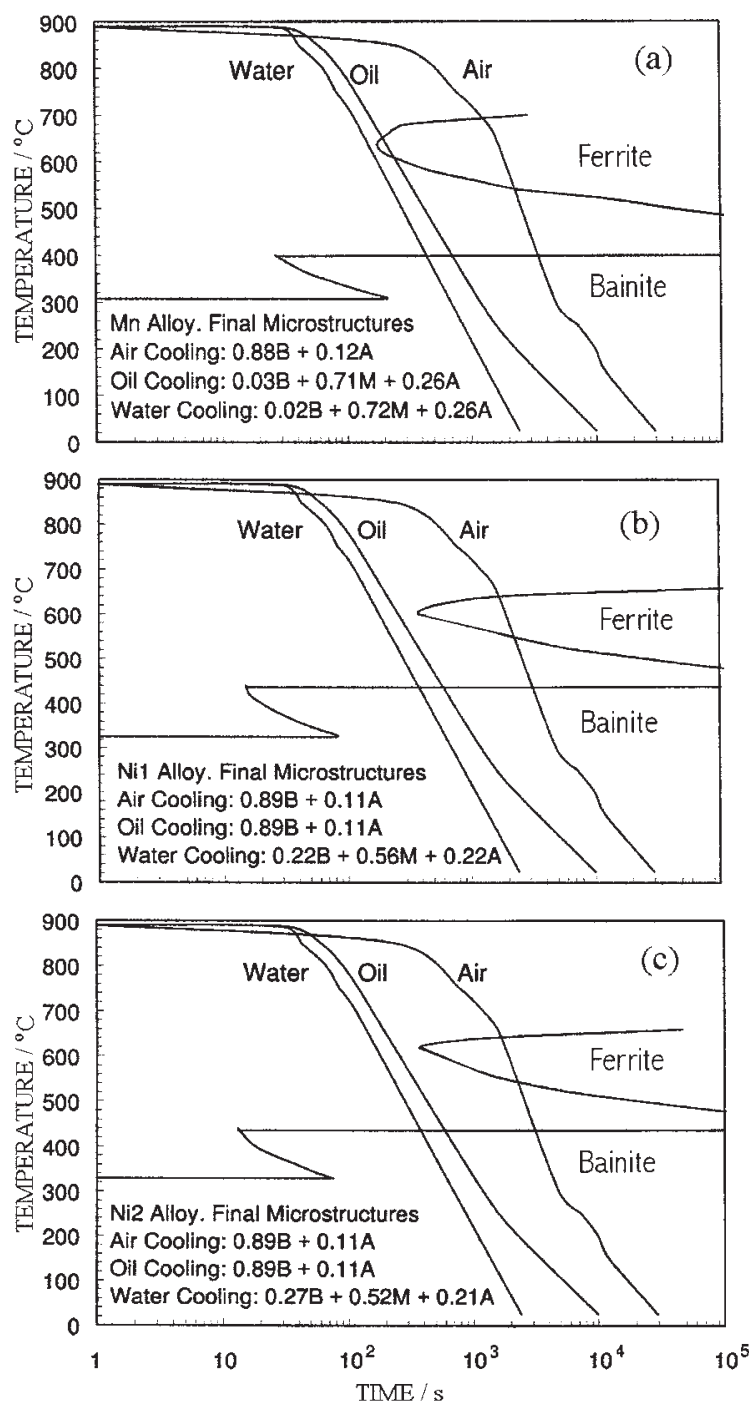

a $\mathrm{Mn}$ alloy; $b \mathrm{Ni1}$ alloy; $c \mathrm{Ni2}$ alloy

2 Calculated TTT diagrams for initiation of transformation: cooling curves representative of core of steel bar $(210 \mathrm{~mm}$ dia.) are superimposed on TTT diagrams only to give rough indication of hardenability since should strictly be plotted on continuous cooling transformation diagrams ( $B, M$, and $A$ denote bainite, martensite, and austenite respectively)

was reduced to $3 \cdot 5 \%$ to increase the residual austenite carbon content without significantly sacrificing hardenability. For the Mn alloy, the best hardenability was achieved by adding $1.30 \% \mathrm{Cr}$ without changes in manganese content

5. Commercial alloys inevitably contain phosphorus and other impurities. An addition of $0 \cdot 25 \%$ Mo was made to reduce impurity embrittlement and to increase hardenability. This addition shifted the $T_{0}^{\prime}$ curve to lower austenite carbon concentrations and hence the molybdenum addition was limited to $0 \cdot 25 \%$.

6. Vanadium was added to restrict austenite grain growth during the austenitising heat treatment.

The compositions of the alloys that have been proposed following a large number of theoretical investigations, are

Table 2 Chemical compositions of designed alloys, wt-\%

\begin{tabular}{llllllll}
\hline Alloy & $\mathrm{C}$ & $\mathrm{Si}$ & $\mathrm{Mn}$ & $\mathrm{Cr}$ & $\mathrm{Mo}$ & $\mathrm{Ni}$ & $\mathrm{V}$ \\
\hline $\mathrm{Mn}$ & 0.30 & 1.5 & 2.00 & 1.30 & 0.25 & $\ldots$ & 0.1 \\
$\mathrm{Ni1}$ & 0.30 & 1.5 & $\ldots$ & 1.44 & 0.25 & 3.5 & 0.1 \\
$\mathrm{Ni2}$ & 0.30 & 1.5 & $\ldots$ & 1.44 & 0.25 & 3.5 & $\ldots$ \\
\hline
\end{tabular}

given in Table 2. The calculated TTT diagrams representing the initiation of transformation are shown in Fig. 2. Also plotted are representative cooling curves ${ }^{27}$ simply to give an indication of hardenability. The curves should really be plotted on continuous cooling transformation diagrams, where the transformation curves would be displaced to longer times. The calculated microstructures included in Fig. 2 are, on the other hand, rigorous, and were obtained using the methods described in Refs. 28 and 29. To form a mixed microstructure of bainite and austenite by continuous cooling, it is necessary to avoid polygonal ferrite and pearlite transformations. The diagrams suggest that the Ni1 and $\mathrm{Ni} 2$ alloys have enough hardenability if the steel is cooled in oil. In that case, the final microstructure in both steels is predicted to be 0.89 bainite and 0.11 austenite. Owing to the high degree of transformation to bainite that takes place, the majority of the retained austenite is expected to be present as films between the subunits of bainitic ferrite. This should result in a microstructure having optimum toughness. Furthermore, for the Mn alloy, a bainite rich microstructure can be obtained by air cooling, but it is possible that some polygonal ferrite may form. However, because of the slow kinetics at temperatures as low as $600^{\circ} \mathrm{C}$, it is likely that any polygonal ferrite will be very limited. The tensile properties calculated using the deformation model described above, are given in Table 3 : very high strength is expected from the novel alloys.

\section{Conclusions}

In steels containing sufficient quantities of silicon, it is possible to obtain a microstructure consisting of a mixture of bainitic ferrite, carbon enriched retained austenite, and some martensite. The mechanism by which bainite grows, places strict limits on the temperature range for transformation and on the maximum fraction of transformation that can ever be achieved. These criteria are embedded in the concept of the $T_{0}^{\prime}$ curve. Thus, thermodynamic theory relying on the $T_{0}^{\prime}$ concept has been used to design an optimum microstructure which avoids large regions of austenite known to be detrimental for toughness.

At the same time, detailed kinetic theory has been used to ensure that the hardenability of the steel is sufficient for the specified industrial application and that the microstructure can be generated by continuous cooling transformation. A model for strength has been developed to guide the design process.

The compositions of $\mathrm{Fe}-0 \cdot 2 \mathrm{C}-2 \mathrm{Si}-3 \mathrm{Mn}$ and $\mathrm{Fe}-$ $0 \cdot 4 \mathrm{C}-2 \mathrm{Si}-4 \mathrm{Ni}$ alloys from previous studies have been used to propose new alloys optimised with respect to strength and toughness. Three new alloys have been proposed as new high strength bainitic steels. The theoretical design of their composition has been made through knowledge of phase transformation theory.

\section{Acknowledgements}

This work was carried out as part of Technology Group 4 (Materials and Structures) of the MoD Corporate Research

Table 3 Tensile strength levels expected from novel alloys

\begin{tabular}{lll}
\hline Alloy & $\begin{array}{l}\text { Yield strength, } \\
\mathrm{MPa}\end{array}$ & $\begin{array}{l}\text { Ultimate tensile strength, } \\
\mathrm{MPa}\end{array}$ \\
\hline $\mathrm{Mn}$ & 2271 & 2341 \\
$\mathrm{Ni} 1$ & 1634 & 2243 \\
$\mathrm{Ni2}$ & 1964 & 2321 \\
\hline
\end{tabular}


Programme. The authors would like to thank Professor A. Windle for the provision of laboratory facilities at the University of Cambridge.

\section{References}

1. S. J. MATAS and R. F. HEHEMANN: Trans. AIME, 1961, 221, 179 185.

2. R. ENTIN: in 'Decomposition of austenite by diffusional processes', (ed. V. F. Zackay and H. I. Aaronson), 295-311; 1962, New York, Interscience.

3. R. F. HEHEMANN: in 'Phase transformations', 397-432; 1970 , Metals Park, OH, American Society for Metals.

4. T. LYMAN and A. R. TROIANO: Trans. AIME, 1945, 162, 196.

5. R. LeHOUILliER, G. BEGIN, and A. DUBE: Metall. Trans., 1971, 2, 2645.

6. H. K. D. H. BHADESHIA and D. v. EDMONDS: Metall. Trans. A, 1979, 10A, 895-907.

7. H. K. D. H. BHADESHIA and D. V. EDMONDS: Acta Metall., 1980 28, $1265-1273$

8. H. K. D. H. BHADESHIA and D. v. EDMONDS: Met. Sci., 1983, 17, $411-419$.

9. H. K. D. H. BHADESHIA and D. v. EDMONDS: Met. Sci., 1983, 17, $420-425$.

10. v. T. T. MIIHKINEN and D. v. EDMONDS: Mater. Sci. Technol., 1987, 3, 422-431.

11. V. T. T. MIIHKINEN and D. V. EDMONDS: Mater. Sci. Technol., 1987, 3, 432-440.

12. v. T. T. MIIHKINEN and D. v. EDMONDS: Mater. Sci. Technol., $1987,3,441-449$.
13. H. K. D. H. BHADESHIA: Mater. Sci. Technol., 1999, 15, $22-29$.

14. F. G. CABALLERO, H. K. D. H. BHADESHIA, K. J. A. MAWELLA, D. G. JONES, and P. BROWN: Mater. Sci. Technol., 2001, 17, 517-522.

15. H. K. D. H. BHADESHIA: Acta Metall., 1981, 29, 1117-1130.

16. H. K. D. H. BHADESHIA and A. R. WAUGH: Acta Metall., 1982, 30, $775-784$.

17. L. C. CHANG and H. K .D. H. BHADEShiA: Mater. Sci. Eng., 1994, A184, L17-20.

18. I. STARK, G. D. W. SMITH, and H. K. D. H. BHADEShia: in 'Solid $\rightarrow$ solid phase transformations', (ed. G. W. Lorimer), $211-215 ; 1988$, London, The Institute of Metals.

19. H. K. D. H. BHADESHIA: Met. Sci., 1982, 16, 159- 165.

20. G. E. DIETER: 'Mechanical metallurgy', 138; 1961, New York, McGraw-Hill.

21. y. soyama: J. Soc. Mater. Sci., Kyoto, 1966, 15, 17.

22. Y. TOMOTA, K. KUROKI, and I. TAMURA: Tetsu-to-Hagane (J. Iron Steel Inst. Jpn), 1975, 61, 107.

23. y. TOMOtA, K. KUROKI, T. MORI, and I. TAMURA: Mater. Sci. Eng., 1976, 24, 85-94.

24. C. H. YOUNG and H. K. D. H. BHADEShIA: Mater. Sci. Technol., 1994, 10, 209-214.

25. A. P. COLDREN, R. L. CRYDERMAN, and M. SEMCHYSHEN: 'Steel strengthening mechanisms', 17; 1969, Ann Arbor, MI, Climax Molybdenum

26. B. P. J. SANDVIK and H. P. NEVAlAINEN: Met. Technol., 1981, 15, $213-220$.

27. DERA Technical Note DRA/WSS/WT6/CR/93 2/1.0, Defence Evaluation Research Agency, Farnborough, Hants, UK, 1993.

28. N. CHESTER and H. K. D. H. BHADESHIA: J. Phys. (France) IV, 1997, 7, $41-46$.

29. S. J. JONES and H. K. D. H. BHADESHIA: Acta Mater., 1997, 45, $2911-2920$ 